\title{
Treatment outcomes in metastatic and localized high-grade salivary gland cancer: high chance of cure with surgery and post-operative radiation in T1-2 N0 high-grade salivary gland cancer
}

\author{
Jeon Yeob Jang ${ }^{1}$, Nayeon Choi ${ }^{2}$, Young-Hyeh Ko ${ }^{3}$, Man Ki Chung ${ }^{2}$, Young-lk Son², Chung-Hwan Baek²,
} Kwan-Hyuck Baek ${ }^{4^{*}}$ and Han-Sin Jeong ${ }^{2^{*}}$ (D)

\begin{abstract}
Background: High-grade salivary gland cancer is a distinct clinical entity that has aggressive disease progression and early systemic spread. However, because of the rarity of the disease, the clinical outcomes, prognostic factors and clinical decision on the optimal treatments have not been fully understood.

Methods: In this study, we retrospectively analyzed the clinical data of 124 patients with high-grade salivary gland cancers and performed multivariate survival analyses to evaluate the clinico-pathological factors affecting the treatment outcomes.

Results: The 5-year disease-specific survival was $63.4 \%$ in patients with high-grade salivary gland cancers. Among the clinico-pathological factors, presence of lymph node metastasis (hazard ratio 5.63, 95\% confidence interval 2.64-12.03, $P<0.001$ ) and distant metastasis (hazard ratio 4.59, 95\% confidence interval $2.10-10.04, P<0.001$ ) at diagnosis were the most potent unfavorable prognostic factors. Importantly, patients with early-stage disease ( $\mathrm{T} 1-2 \mathrm{NOM0}$ ) showed apparently a relatively excellent prognosis (93.2\% 5-year disease-specific survival); meanwhile $\mathrm{N}(+)$ and M1 status at diagnosis resulted in dismal outcomes (44.6 and 21.1\% 5-year disease-specific survival, respectively). On comparing surgery alone as a treatment modality, surgery plus postoperative radiation significantly benefited the patients, but the difference between adjuvant radiation and chemoradiation was not found to be significant. Pathological subtypes of high-grade salivary gland cancers were not significantly associated with prognosis.
\end{abstract}

Conclusions: Despite of an overall unfavorable prognosis in high-grade salivary gland cancer, patients with early-stage disease are expected to have excellent prognosis (over 90\% survival rates) with surgery plus adjuvant radiation, which may implicate the patients' consultation, therapeutic decision making, and the need for early detection of the disease.

Keywords: Salivary gland neoplasm, High-grade pathology, Treatment outcomes, Prognosis

\footnotetext{
* Correspondence: khbaek@skku.edu; hansin.jeong@gmail.com

${ }^{4}$ Department of Molecular and Cellular Biology, Samsung Biomedical

Research Institute, Sungkyunkwan University School of Medicine, Suwon, Republic of Korea

${ }^{2}$ Department of Otorhinolaryngology - Head and Neck Surgery, Samsung

Medical Center, Sungkyunkwan University School of Medicine, 81 Irwon-ro,

Gangnam-gu, Seoul 06351, Republic of Korea

Full list of author information is available at the end of the article
}

(c) The Author(s). 2018 Open Access This article is distributed under the terms of the Creative Commons Attribution 4.0 International License (http://creativecommons.org/licenses/by/4.0/), which permits unrestricted use, distribution, and reproduction in any medium, provided you give appropriate credit to the original author(s) and the source, provide a link to the Creative Commons license, and indicate if changes were made. The Creative Commons Public Domain Dedication waiver (http://creativecommons.org/publicdomain/zero/1.0/) applies to the data made available in this article, unless otherwise stated. 


\section{Background}

Salivary gland cancer is rare $(0.6-1.4$ per 100,000$)$ and arises from the major and minor salivary glands, and it also has diverse histopathology comprising 21-22 subtypes [1-4]. Diagnosis, estimation of prognosis and decision on the optimal treatments of salivary gland cancer need to be improved because of the rarity of this disease and pathological diversity [5]. Previously, we and other researchers have reported that the critical decision making in the diagnosis and treatment of salivary gland cancer should be based on the histological grade of tumors, and not on the specific pathological subtype [6-8].

Low-grade salivary gland cancers have excellent outcomes even after marginal excision of tumors, similar to those for benign salivary gland tumors $[9,10]$. Thus, it seems to be favorable with the current standard treatment modalities (surgery with/without radiation), if we can correctly diagnose the disease entity pathologically. However, among salivary gland cancers, high-grade salivary gland cancers, such as salivary duct carcinomas, have quite different characters in terms of the clinical course and treatment outcomes [11-14]. Aggressive disease progression and early systemic spread are common findings that are observed in these patients $[6,15,16]$. As a result, high-grade salivary gland cancers have one of the highest cancer mortality rates (less than 50\% survival in 5 years) among all head and neck cancers [12, 17].

Salivary gland cancers have diverse histopathological subtypes which leads that most of the previous studies have focused on the clinical analyses depending on the specific subtypes or all pathological diagnoses together [18-20]. However, specific pathological diagnosis could not be achieved before detailed examination of the surgical specimen, and preoperative tests are usually insufficient for diagnosing specific pathological subtypes. Thus, overall tumor grade might be a more clinically relevant indicator with respect to treatment decision and prognosis estimation, and it can be diagnosed preoperatively even by fine needle aspiration cytology or core needle biopsy [7, 21, 22].

In line with these assumptions, we evaluated the clinical outcomes of high-grade salivary gland cancers as a whole in this paper. Key question was what could be the important clinical factors that determine the prognosis in patients with high-grade salivary gland cancers. This effort is expected to allow the potential risk stratification of this rare disease with clinical implications.

\section{Methods}

This was a retrospective analysis using clinical data of patients with salivary gland carcinomas, where treatments had followed the National Comprehensive Cancer Network (NCCN) guideline [23]. The study protocol was approved by the Institutional Review Board of
Samsung Medical Center, Seoul, Korea. The data used in the study was de-identified.

\section{Study subjects}

The initial study population included 540 patients diagnosed as having salivary gland cancer at our institution from 1995 to 2014. The inclusion criteria for this study were patients who had (i) high-grade salivary gland cancers confirmed by surgical pathology; (ii) no previous treatments for high-grade salivary gland cancer; (iii) more than two years of follow-up from the end of definitive treatment. Patients diagnosed as having metastatic tumors to the salivary gland from other malignancies or recurrent tumors, and those with a previous history of head and neck cancer or irradiation to the head and neck area were excluded. Based on these criteria, clinical data of 139 patients was collected in this study, but 15 patients were further excluded because of incomplete clinical and pathological information, leaving a final $n=124$ available for the analysis.

Most of the patients $(n=103)$ had initially undergone curative surgery for primary tumors with or without neck dissection. Based on the surgical pathology reports, each tumor was reassigned a pathological tumor-node-metastasis (pTNM) stage using the 7th edition the American Joint Committee on Cancer staging manual [24]. Core needle biopsy or surgical biopsy was conducted to make a pathological diagnosis in the remaining patients $(n=21)$, who had received non-surgical management options, where $\mathrm{cT} / \mathrm{cN}$ was used in cases instead of $\mathrm{pT} / \mathrm{pN}$.

\section{Pathological diagnosis}

To confirm the diagnosis of high-grade salivary gland cancer, a senior pathologist (YHK) with over 10 years' experience in pathological diagnosis of salivary gland tumors reviewed the surgical specimens. Pathological features, such as extra-parenchymal (extra-glandular) extension, perineural/nerve invasion, lymphovascular invasion/tumor emboli, and resection margin status were redefined in each specimen. In cases of node-positive disease, the number of metastatic nodes and the presence of extracapsular spread were also recorded.

High-grade salivary gland cancer included the following pathology subtypes; salivary duct carcinoma, primary squamous cell carcinoma, solid type adenoid cystic carcinoma [25, 26], high-grade mucoepidermoid carcinoma $[18,27]$, high-grade adenocarcinoma [28], high-grade carcino-sarcoma and poorly differentiated carcinoma. They were diagnosed based on the histo-morphologic pattern and cytologic features, and only those tumors showing high-grade histology were included. If needed, several immunohistochemical stains were performed to differentiate the pathological subtypes. In cases of squamous cell carcinomas of the salivary glands, we employed all available diagnostic modalities to exclude 
Table 1 Characteristics of subjects with total high-grade salivary gland cancers $(n=124)$ and resectable high-grade salivary gland cancers $(n=103)$

\begin{tabular}{|c|c|c|}
\hline Characteristics & No. & $\%$ \\
\hline \multicolumn{3}{|l|}{ Total high-grade salivary gland cancers $(n=124)$} \\
\hline Age [years; median (range)] & $\begin{array}{l}61 \\
(31-89)\end{array}$ & \\
\hline Gender (Male/Female) & $95 / 29$ & $76.6 / 23.4$ \\
\hline \multicolumn{3}{|l|}{ Tumor site } \\
\hline Parotid gland & 84 & 67.7 \\
\hline Submandibular gland & 38 & 30.6 \\
\hline Sublingual gland and minor salivary gland & 2 & 1.6 \\
\hline \multicolumn{3}{|l|}{ T classification } \\
\hline $\mathrm{T} 1$ & 20 & 16.1 \\
\hline $\mathrm{T} 2$ & 44 & 35.5 \\
\hline T3 & 23 & 18.5 \\
\hline T4 & 37 & 29.8 \\
\hline \multicolumn{3}{|l|}{ N classification } \\
\hline No & 63 & 50.8 \\
\hline N1 & 10 & 8.1 \\
\hline N2-3 & 51 & 41.1 \\
\hline \multicolumn{3}{|l|}{ M classification } \\
\hline Mo & 109 & 87.9 \\
\hline M1 & 15 & 12.1 \\
\hline \multicolumn{3}{|l|}{ AJCC TNM stage } \\
\hline I & 14 & 11.3 \\
\hline$\|$ & 24 & 19.4 \\
\hline III & 16 & 12.9 \\
\hline IV & 70 & 56.5 \\
\hline \multicolumn{3}{|l|}{ Pathological diagnosis } \\
\hline Salivary duct carcinoma & 74 & 59.7 \\
\hline Squamous cell carcinoma, primary* & 13 & 10.5 \\
\hline Adenoid cystic carcinoma, solid type & 12 & 9.7 \\
\hline Mucoepidermoid carcinoma, high-grade & 9 & 7.3 \\
\hline Adenocarcinoma, high-grade & 6 & 4.8 \\
\hline Atypical high-grade carcinoma & 3 & 2.4 \\
\hline Carcino-sarcoma, high-grade & 4 & 3.2 \\
\hline Poorly differentiated carcinoma & 3 & 2.4 \\
\hline \multicolumn{3}{|l|}{ Treatment modalities } \\
\hline Surgery alone & 13 & 10.5 \\
\hline Surgery + adjuvant radiation & 62 & 50.0 \\
\hline Surgery + adjuvant radiation + chemotherapy & 28 & 22.6 \\
\hline $\begin{array}{l}\text { Initial non-surgical local treatment (radiation or } \\
\text { chemoradiation) }\end{array}$ & 3 & 2.4 \\
\hline Chemotherapy or palliative treatment & 18 & 14.5 \\
\hline
\end{tabular}

Clinical outcomes
Table 1 Characteristics of subjects with total high-grade salivary gland cancers $(n=124)$ and resectable high-grade salivary gland cancers $(n=103)$ (Continued)

\begin{tabular}{|c|c|c|}
\hline Characteristics & No. & $\%$ \\
\hline Disease-specific death & 39 & 31.5 \\
\hline $\begin{array}{l}\text { Event-free follow-up period } \\
\text { [months; median (range)] }\end{array}$ & $\begin{array}{l}109 \\
{[2-188]}\end{array}$ & \\
\hline All-cause death & 44 & 35.5 \\
\hline \multicolumn{3}{|l|}{ Resectable high-grade salivary gland caners $(n=103)$} \\
\hline \multicolumn{3}{|l|}{ Surgery for primary tumor } \\
\hline $\begin{array}{l}\text { R0 resection } \\
\text { (cancer cells absent at the resection margin) }\end{array}$ & 97 & 94.2 \\
\hline $\begin{array}{l}\text { R1 resection } \\
\text { (cancer cells present at the resection margin) }\end{array}$ & 6 & 5.8 \\
\hline \multicolumn{3}{|l|}{ Neck dissection } \\
\hline No & 31 & 30.1 \\
\hline Selective neck lymph node dissection & 30 & 29.1 \\
\hline Comprehensive neck lymph node dissection & 42 & 40.8 \\
\hline \multicolumn{3}{|l|}{ Pathological risk factors } \\
\hline Perineural invasion $(\mathrm{Y} / \mathrm{N})$ & $13 / 90$ & $12.6 / 87.4$ \\
\hline Lymphovascular invasion (Y/N) & $16 / 87$ & $15.5 / 84.5$ \\
\hline $\begin{array}{l}\text { Extra-parenchymal (Extra-glandular) } \\
\text { extension of tumor }(\mathrm{Y} / \mathrm{N})\end{array}$ & $45 / 58$ & $43.7 / 56.3$ \\
\hline $\begin{array}{l}\text { Extra-capsular spread of lymph node } \\
\text { metastasis }(\mathrm{Y} / \mathrm{N})\end{array}$ & $26 / 77$ & $25.2 / 74.8$ \\
\hline \multicolumn{3}{|l|}{ Clinical outcomes } \\
\hline Recurrence & 40 & 38.8 \\
\hline $\begin{array}{l}\text { Recurrence-free period [months; } \\
\text { median (range)] }\end{array}$ & $\begin{array}{l}109 \\
{[2-188]}\end{array}$ & \\
\hline Disease-specific death & 27 & 26.2 \\
\hline $\begin{array}{l}\text { Event-free follow-up period [months; } \\
\text { median (range)] }\end{array}$ & $\begin{array}{l}123 \\
{[2-188]}\end{array}$ & \\
\hline
\end{tabular}

\section{Abbreviation:}

AJCC TNM stage: 7th edition of the American Joint Committee on Cancer staging manuals (2010)

$\mathrm{Y}$ : presence, $\mathrm{N}$ : absence

*No evidence of squamous cell carcinomas in other sites, in imaging studies and clinical follow-ups.

the possibility of metastasis to the intra-glandular lymph nodes and confirmed the diagnosis of primary squamous cell carcinomas arising from the salivary gland with clinical follow-ups. Equivocal pathological diagnoses were discussed during intra-departmental consultation, and some patients were diagnosed by external review.

\section{Statistical analyses}

In our cohort, we evaluated recurrence and death event according to the treatment modalities, $\mathrm{T} / \mathrm{N}$ classification and pathological characteristics. $\mathrm{pT} / \mathrm{pN}$ (or $\mathrm{cT} / \mathrm{cN}$ in patients with non-surgical management) was used to classify tumor extent. Baseline variables at diagnosis of high-grade salivary gland cancers (age, gender, and primary site) were also considered as the variables for predicting the outcome. 
The primary endpoints were disease-specific survival (DSS) in all patients and recurrence-free survival (RFS) in patients with resectable high-grade salivary gland cancers. DSS, RFS and overall survival (OS) were calculated as the time elapsed from the end of definitive treatments until the time of recurrence and death, respectively. The patients without any events (recurrence or death) at the last clinical follow-up were censored. Survival curves were estimated using the Kaplan-Meier method, and group differences were tested using the log-rank test. Prognostic significance of variables was assessed by univariate and multivariate analyses using the Cox proportional hazard model. Statistical analyses were performed using SPSS version 20.0 (IBM Corporation, Armonk, NY, USA). All tests were two-sided and $P<0.05$ indicated statistical significance.

\section{Results}

\section{Characteristics of the study subjects}

We analyzed the clinical and pathological data of 124 patients with pathologically proven high-grade salivary gland cancer (Table 1). The number of male patients was three times higher than that of female patients $(\mathrm{M}: \mathrm{F}=3: 1)$ with a mean age of 61 years (range 31 to 89 years). Approximately two-thirds of high-grade salivary gland cancers were found in the parotid gland in our series.

Primary tumor extent was distributed evenly across $\mathrm{T}$ classification with $51.6 \%$ of $\mathrm{T} 1-2$ and $48.3 \%$ of $\mathrm{T} 3-4$. Similarly, half of high-grade salivary gland cancers showed regional lymph node metastasis $(49.2 \%)$ at diagnosis. Further, 15 patients $(12.1 \%)$ already had distant metastasis to the lung $(n=12)$, and lung plus bone $(n=3)$. Among the patients without clinical evidence of systemic spread of disease (M0) $(n=109)$, six patients could not receive the initial surgical treatment because of poor medical condition $(n=4)$ and refusal of surgery $(n=2)$. Thus, 21 patients had received initial non-surgical local treatment or chemotherapy, and 103 subjects had undergone curative surgery for high-grade salivary gland cancers. During clinical courses, we found 39 disease-specific deaths (31.5\%) and 44 all-cause deaths (35.5\%).

Table 2 Disease-specific survival in patients with high-grade salivary gland cancers $(n=124)$

\begin{tabular}{|c|c|c|c|c|c|c|c|c|c|}
\hline \multirow[t]{2}{*}{ Factors (Number) } & \multicolumn{3}{|c|}{ Univariate model } & \multicolumn{3}{|c|}{ Multivariate model \#1 } & \multicolumn{3}{|c|}{ Multivariate model \#2 } \\
\hline & $\mathrm{HR}$ & $95 \% \mathrm{Cl}$ & $P$ & $\mathrm{HR}$ & $95 \% \mathrm{Cl}$ & $P$ & $\mathrm{HR}$ & $95 \% \mathrm{Cl}$ & $P$ \\
\hline Age (years) & 1.021 & $0.994-1.049$ & 0.135 & & & & & & \\
\hline Gender (Male/Female) (95/29) & 1.446 & $0.636-3.290$ & 0.379 & & & & & & \\
\hline \multicolumn{10}{|l|}{ Primary site } \\
\hline Parotid gland (84) & 1 (Ref.) & & & & & & & & \\
\hline Non-parotid gland (40) & 1.246 & $0.640-2.427$ & 0.518 & & & & & & \\
\hline \multicolumn{10}{|l|}{ TNM categories } \\
\hline T3-4/T1-2 (60/64) & 1.880 & $0.980-3.608$ & 0.058 & 0.824 & $0.412-1.648$ & 0.584 & 1.145 & $0.593-2.212$ & 0.687 \\
\hline N1-3/N0 (61/63) & 5.573 & $2.651-11.713$ & $<0.001$ & 8.669 & $3.787-19.842$ & $<0.001$ & 5.632 & $2.638-12.027$ & $<0.001$ \\
\hline M1/M0 (15/109) & 4.550 & $2.139-9.680$ & $<0.001$ & & & & 4.591 & $2.100-10.035$ & $<0.001$ \\
\hline \multicolumn{10}{|l|}{ Pathological diagnosis } \\
\hline Salivary duct carcinoma (74) & 1 (Ref.) & & & & & & & & \\
\hline Squamous cell carcinoma, primary (13) & 1.271 & $0.480-3.368$ & 0.629 & & & & & & \\
\hline Adenoid cystic carcinoma, solid type (12) & 1.422 & $0.537-3.766$ & 0.479 & & & & & & \\
\hline Mucoepidermoid carcinoma, high-grade (9) & 1.094 & $0.326-3.673$ & 0.885 & & & & & & \\
\hline Adenocarcinoma, high-grade (6) & 0.386 & $0.052-2.870$ & 0.352 & & & & & & \\
\hline Others $^{*}(10)$ & 1.681 & $0.501-5.642$ & 0.440 & & & & & & \\
\hline \multicolumn{10}{|l|}{ Treatment modalities } \\
\hline Surgery (13) & 1 (Ref) & & & 1 (Ref.) & & & & & \\
\hline Surgery + radiation (62) & 1.247 & $0.372-4.182$ & 0.721 & 0.761 & $0.216-2.678$ & 0.671 & & & \\
\hline Surgery + radiation + chemotherapy (28) & 0.418 & $0.084-2.075$ & 0.286 & 0.134 & $0.025-0.709$ & 0.018 & & & \\
\hline Others $^{\dagger}(21)$ & 4.589 & $1.281-16.434$ & 0.019 & 2.786 & $0.731-10.617$ & 0.133 & & & \\
\hline
\end{tabular}

M1 status was significantly associated with the application of the so-called other treatment modalities (initial non-surgical, chemotherapy or palliative treatments); thus, we built two separate multivariate models using independent variables Abbreviation:

HR Hazard ratio, Cl Confidence interval

Others ${ }^{*}$ : Atypical high-grade carcinoma, high-grade carcino-sarcoma, poorly differentiated carcinoma

Others $^{\dagger}$ : Initial non-surgical local treatment (radiation or chemoradiation), chemotherapy or palliative treatment 
In all patients, the pathological diagnosis was made by surgical pathology or biopsy. Notably, salivary duct carcinoma, excluding the low-grade, non-invasive form of salivary duct carcinoma, comprised $59.7 \%$ of high-grade salivary gland cancers, followed by primary squamous cell carcinoma, solid type adenoid cystic carcinoma and high-grade mucoepidermoid carcinoma (7.3-10.5\%).

Next, we analyzed the clinical data of patients that underwent an initial curative surgery $(n=103)$. Cervical lymph node dissection was performed in $70 \%$ of the patients, however it was not performed in the remaining $30 \%$ of the patients, mainly because of small tumor burden with low suspicion of high-grade pathology on pre-operative work-ups, even though these were also proved to be high-grade salivary gland cancer on the final surgical pathology. In these patients, the status of regional lymph nodes was confirmed by radiological findings or clinical follow-ups. Pathological risk factors were found in 12.6 to $43.7 \%$ of the patients. After completion of the recommended treatments, 40 recurrences (4 at the primary sites, 11 in the regional lymph nodes and 25 in the distant organs) were detected and 27 disease-specific deaths occurred.

\section{Disease-specific and overall survival of patients with high-grade salivary gland cancers}

The 5-year DSS and OS rates in patients diagnosed as having high-grade salivary gland cancer were 63.4 and $61.4 \%$ respectively $(n=124)$. In addition, patients with systemic disease spread survived only a median period of 20 months with a range from 2 to 109 months $(n=15$ at diagnosis and $n=26$ detected during the clinical course). As responsible prognostic factors, lymph node and distant metastases at presentation were identified as the most significant indicators of poor survival (Tables 2 and 3). Intriguingly, specific pathological subtypes of high-grade salivary gland cancers were not major determinants of patient survival, suggesting the need for a clinical approach to high-grade salivary gland cancer as a whole.

Next, we performed multivariate survival analyses using the variables with significant values on the univariate analyses. Because M1 status at diagnosis was the

Table 3 Overall survival in patients with high-grade salivary gland cancers $(n=124)$

\begin{tabular}{|c|c|c|c|c|c|c|c|c|c|}
\hline \multirow[t]{2}{*}{ Factors (Number) } & \multicolumn{3}{|c|}{ Univariate model } & \multicolumn{3}{|c|}{ Multivariate model \#1 } & \multicolumn{3}{|c|}{ Multivariate model \#2 } \\
\hline & $\mathrm{HR}$ & $95 \% \mathrm{Cl}$ & $P$ & $\mathrm{HR}$ & $95 \% \mathrm{Cl}$ & $P$ & $\mathrm{HR}$ & $95 \% \mathrm{Cl}$ & $P$ \\
\hline Age (years) & 1.032 & $1.005-1.059$ & 0.019 & 1.038 & $1.008-1.069$ & 0.012 & 1.054 & $1.024-1.084$ & $<0.001$ \\
\hline Gender (Male/Female) (95/29) & 1.396 & $0.645-3.022$ & 0.397 & & & & & & \\
\hline \multicolumn{10}{|l|}{ Primary site } \\
\hline Parotid gland (84) & 1 (Ref.) & & & & & & & & \\
\hline Non-parotid gland (40) & 1.286 & $0.687-2.405$ & 0.432 & & & & & & \\
\hline \multicolumn{10}{|l|}{ TNM categories } \\
\hline Т3-4/T1-2 (60/64) & 1.785 & $0.955-3.336$ & 0.069 & 0.807 & $0.405-1.609$ & 0.542 & 0.964 & $0.505-1.839$ & 0.912 \\
\hline N1-3/N0 (61/63) & 5.002 & $2.492-10.042$ & $<0.001$ & 9.263 & $4.025-21.317$ & $<0.001$ & 7.010 & $3.176-15.472$ & $<0.001$ \\
\hline M1/M0 (15/109) & 4.171 & $1.978-8.795$ & $<0.001$ & & & & 4.716 & $2.148-10.357$ & $<0.001$ \\
\hline \multicolumn{10}{|l|}{ Pathological diagnosis } \\
\hline Salivary duct carcinoma (74) & 1 (Ref.) & & & & & & & & \\
\hline Squamous cell carcinoma, primary (13) & 1.434 & $0.582-3.534$ & 0.433 & & & & & & \\
\hline Adenoid cystic carcinoma, solid type (12) & 1.381 & $0.523-3.646$ & 0.515 & & & & & & \\
\hline Mucoepidermoid carcinoma, high-grade (9) & 1.458 & $0.501-4.246$ & 0.489 & & & & & & \\
\hline Adenocarcinoma, high-grade (6) & 0.370 & $0.050-2.752$ & 0.332 & & & & & & \\
\hline Others $^{*}(10)$ & 2.059 & $0.707-5.999$ & 0.186 & & & & & & \\
\hline \multicolumn{10}{|l|}{ Treatment modalities } \\
\hline Surgery (13) & 1 (Ref) & & & 1 (Ref.) & & & & & \\
\hline Surgery + radiation (62) & 0.945 & $0.355-2.514$ & 0.909 & 0.720 & $0.254-2.044$ & 0.537 & & & \\
\hline Surgery + radiation + chemotherapy (28) & 0.299 & $0.070-1.276$ & 0.103 & 0.158 & $0.033-0.755$ & 0.021 & & & \\
\hline Others $^{\dagger}(21)$ & 3.282 & $1.115-9.655$ & 0.031 & 1.793 & $0.374-8.602$ & 0.466 & & & \\
\hline
\end{tabular}

M1 status was significantly associated with the application of the so-called other treatment modalities (initial non-surgical, chemotherapy or palliative treatments); thus, we built two separate multivariate models using independent variables Abbreviation:

$H R$ hazard ratio, $\mathrm{Cl}$ confidence interval

Others*: Atypical high-grade carcinoma, high-grade carcino-sarcoma, poorly differentiated carcinoma

Otherst: Initial non-surgical local treatment (radiation or chemoradiation), chemotherapy or palliative treatment 
main determinant of initial non-surgical treatments (multi-collinearity), we separately built two independent multivariate models to minimize interference. In the analyses, we confirmed that lymph node and distant metastases were significant independent predictors of poor disease-specific and overall survival in patients with high-grade salivary gland cancers. In addition, patient age was another significant factor for overall survival (Table 3). Kaplan-Meier survival analyses also showed clear discrimination of the survival plots between non-metastatic and metastatic high-grade salivary gland cancer (Fig. 1). Of note, early stage high-grade salivary gland cancer showed excellent prognosis (93.2\% 5-year DSS), indicating the significance of early diagnosis for improving treatment outcomes.

On comparing surgery alone as a treatment modality, surgery plus postoperative radiation and chemotherapy significantly benefited the patients with high-grade salivary gland cancers, commonly having advanced stage disease (Tables 2 and 3). However, the difference between adjuvant radiation and chemoradiation was not found to be significant. Most of T1-2 diseases were treated with surgery plus radiation, except for a subset of T1 tumors with adequate resection margins on surgery.

\section{Recurrence-free and disease-specific survival of patients} with resectable high-grade salivary gland cancers

Using the patient data with resectable high-grade salivary gland cancer $(n=103)$, we constructed two separate Cox proportional hazard models, because a pathological risk factor, extra-parenchymal extension of the primary tumor was significantly associated with T3 classification (Table 4). Among various clinical and pathological variables, lymph node metastasis was only found to be significant as an independent prognostic factor for poor RFS in patients with resectable high-grade salivary gland cancers, and none of the pathological risk factors showed significance in survival analyses. This result was also consistent with DSS in patients with resectable high-grade salivary gland cancer (Table 5). Similarly, surgery plus postoperative chemoradiation was associated with better DSS than surgery alone. However, no survival difference between adjuvant radiation and chemoradiation was observed, which was same as the results obtained in total patients with high-grade salivary gland cancers (Fig. 2).

\section{Discussion}

High-grade salivary gland cancer is a rare disease entity; however it causes fatal cancer-related consequences in most of the patients. Unfortunately, clinical and basic research studies are limited because of the rarity of the disease, and most of the clinical information on the optimal treatments has been obtained from the retrospective studies.

In our series, the 5-year disease-specific survival in patients with lymph node metastasis was $44.6 \%$ while the disease-specific survival was $63.4 \%$ in all patients with high-grade salivary gland cancers. These results were concordant with the previous studies reporting the estimated survival of $30.6-44.0 \%$ in patients with $\mathrm{N}(+)$

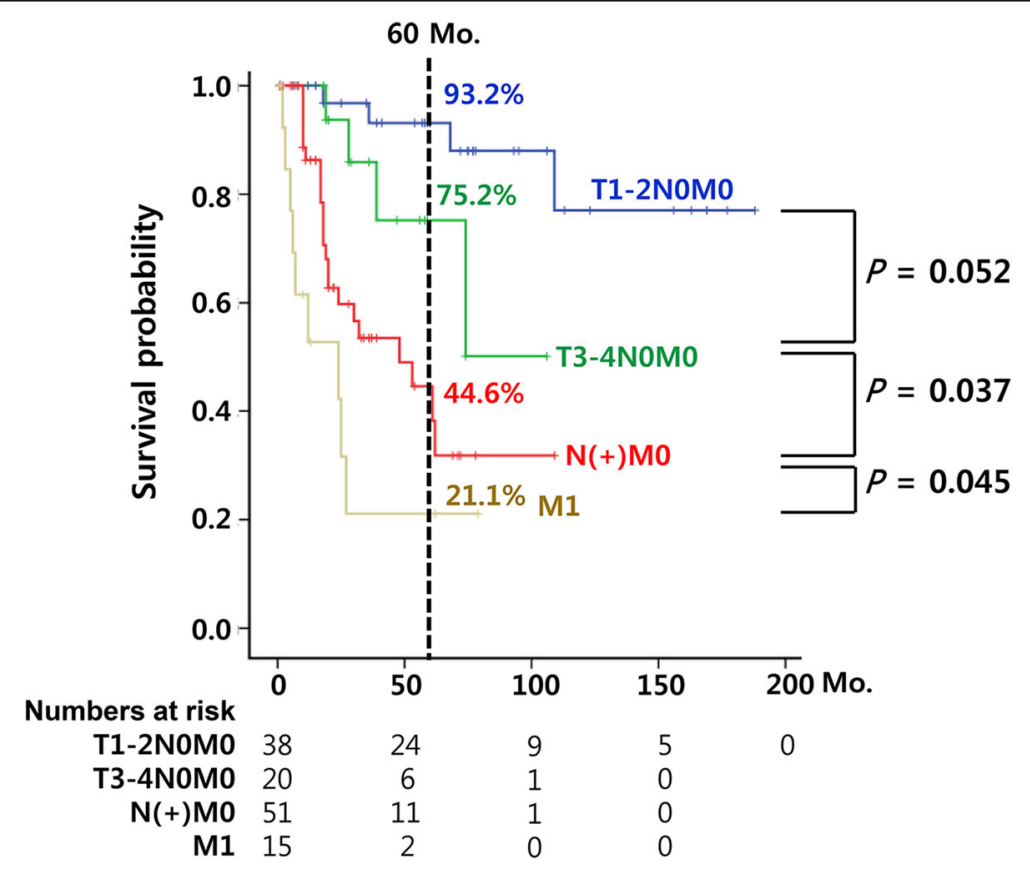

Fig. 1 Survival curves according to the tumor-node-metastasis staging in patients with high-grade salivary gland cancers 
Table 4 Recurrence-free survival in patients with resectable high-grade salivary gland cancers $(n=103)$

\begin{tabular}{|c|c|c|c|c|c|c|c|c|c|}
\hline \multirow[t]{2}{*}{ Factors (Number) } & \multicolumn{3}{|c|}{ Univariate model } & \multicolumn{3}{|c|}{ Multivariate model \#1 } & \multicolumn{3}{|c|}{ Multivariate model \#2 } \\
\hline & $\mathrm{HR}$ & $95 \% \mathrm{Cl}$ & $P$ & $\mathrm{HR}$ & $95 \% \mathrm{Cl}$ & $P$ & $\mathrm{HR}$ & $95 \% \mathrm{Cl}$ & $P$ \\
\hline Age (years) & 1.008 & $0.980-1.036$ & 0.584 & & & & & & \\
\hline Gender (Male/Female) (83/20) & 2.070 & $0.808-5.303$ & 0.130 & & & & & & \\
\hline \multicolumn{10}{|l|}{ Primary site } \\
\hline Parotid gland (69) & 1 (Ref.) & & & & & & & & \\
\hline Non-parotid gland (34) & 1.718 & $0.912-3.237$ & 0.094 & & & & & & \\
\hline \multicolumn{10}{|l|}{ TN categories } \\
\hline T3-4/T1-2 (45/58) & 1.986 & $1.048-3.761$ & 0.035 & 0.984 & $0.460-2.103$ & 0.967 & & & \\
\hline N1-3/N0 (48/55) & 4.489 & $2.241-8.994$ & $<0.001$ & 4.693 & $1.990-11.069$ & $<0.001$ & 4.650 & $1.967-10.994$ & $<0.001$ \\
\hline \multicolumn{10}{|l|}{ Pathological diagnosis } \\
\hline Salivary duct carcinoma (67) & 1 (Ref.) & & & & & & & & \\
\hline Squamous cell carcinoma, primary (9) & 0.226 & $0.031-1.661$ & 0.114 & & & & & & \\
\hline Adenoid cystic carcinoma, solid type (8) & 1.289 & $0.451-3.685$ & 0.635 & & & & & & \\
\hline Mucoepidermoid carcinoma, high-grade (7) & 0.851 & $0.258-2.806$ & 0.791 & & & & & & \\
\hline Adenocarcinoma, high-grade (6) & 0.283 & $0.040-2.162$ & 0.229 & & & & & & \\
\hline Others (6) & 1.847 & $0.556-6.138$ & 0.317 & & & & & & \\
\hline \multicolumn{10}{|l|}{ Treatment modalities } \\
\hline Surgery (13) & 1 (Ref) & & & 1 (Ref) & & & 1 (Ref) & & \\
\hline Surgery + radiation (62) & 1.294 & $0.450-3.719$ & 0.632 & 0.917 & $0.303-2.778$ & 0.879 & 0.912 & $0.301-2.758$ & 0.870 \\
\hline Surgery + radiation + chemotherapy (28) & 1.068 & $0.339-3.359$ & 0.911 & 0.421 & $0.125-1.425$ & 0.164 & 0.421 & $0.125-1.424$ & 0.164 \\
\hline Surgery of primary tumor (R1/R0) (6/97) & 1.126 & $0.347-3.660$ & 0.843 & & & & & & \\
\hline Neck dissection/no neck dissection (72/31) & 1.489 & $0.739-3.000$ & 0.266 & & & & & & \\
\hline \multicolumn{10}{|l|}{ Pathological risk factors } \\
\hline Perineural invasion (Y/N) (13/90) & 1.111 & $0.434-2.846$ & 0.827 & & & & & & \\
\hline Lymphovascular invasion (Y/N) (16/87) & 1.132 & $0.440-2.915$ & 0.797 & & & & & & \\
\hline Extra-parenchymal extension (Y/N) (45/58) & 2.045 & $1.077-3.886$ & 0.029 & & & & 1.006 & $0.469-2.157$ & 0.988 \\
\hline Extra-capsular spread (Y/N) (26/77) & 3.236 & $1.665-6.290$ & 0.001 & 1.799 & $0.850-3.811$ & 0.125 & 1.792 & $0.846-3.795$ & 0.128 \\
\hline
\end{tabular}

T classification (particularly T3) was significantly associated with the presence of extra-parenchymal extension of primary tumors; thus, we built two separate multivariate models using independent variables

Abbreviation:

$H R$ hazard ratio $\mathrm{Cl}$ confidence interval

R1 resection: Cancer cells present at the resection margin, R0 resection: Cancer cells absent at the resection margin

Others (Pathology diagnosis): Atypical high-grade carcinoma, high-grade carcino-sarcoma, poorly differentiated carcinoma

$\mathrm{Y}$ : presence, $\mathrm{N}$ : absence

salivary gland cancers while reporting the estimated survival of $64.3-80.0 \%$ in patients with non-metastatic salivary gland cancers $[12,13,29,30]$. Our data also showed that the patients with systemic disease spread survived only a median period of 20 months, which is concordant with the previous reports indicating the median survival of 15 months after distant metastasis development [15]. To sum up our findings and previous reports, the presence of metastasis to regional lymph node or distant organ is a significant independent prognostic factor for survival in patients with high-grade salivary gland cancers. Meanwhile, high-grade salivary gland cancer that did not have metastasis at presentation showed a relatively favorable outcome $(93.2 \%$ in T1-2N0M0 and
$75.2 \%$ in T3-4N0M0, Fig. 1), even in high-grade pathology while performing surgery plus adjuvant radiation in most patients. Thus, this suggests that early detection or diagnosis of high-grade salivary gland cancer is very important for improving patients' prognosis, before high-grade salivary gland cancer progresses to clinically overt metastasis.

Another interesting point in our study was that there was no significant difference among high-grade subtypes in terms of treatment outcomes and patient survival. High-grade salivary duct carcinoma, which is already known to have a dismal outcome, was the most frequent subtype of high-grade salivary gland cancer in our series, but other pathologic types of 
Table 5 Disease-specific survival in patients with resectable high-grade salivary gland cancers $(n=103)$

\begin{tabular}{|c|c|c|c|c|c|c|}
\hline & \multicolumn{3}{|c|}{ Univariate model } & \multicolumn{3}{|c|}{ Multivariate model } \\
\hline & $\overline{\mathrm{HR}}$ & $95 \% \mathrm{Cl}$ & $P$ & $\overline{\mathrm{HR}}$ & $95 \% \mathrm{Cl}$ & $P$ \\
\hline Age (years) & 1.012 & $0.980-1.045$ & 0.464 & & & \\
\hline Gender (Male/Female) (83/20) & 2.325 & $0.697-7.756$ & 0.170 & & & \\
\hline \multicolumn{7}{|l|}{ Primary site } \\
\hline Parotid gland (69) & 1 (Ref.) & & & & & \\
\hline Non-parotid gland (34) & 1.409 & $0.644-3.081$ & 0.390 & & & \\
\hline \multicolumn{7}{|l|}{ TN categories } \\
\hline T3-4/T1-2 (45/58) & 2.011 & $0.919-4.403$ & 0.080 & 0.744 & $0.285-1.938$ & 0.544 \\
\hline N1-3/N0 (48/55) & 6.115 & $2.509-14.903$ & $<0.001$ & 10.211 & $3.485-29.919$ & $<0.001$ \\
\hline \multicolumn{7}{|l|}{ Pathological diagnosis } \\
\hline Salivary duct carcinoma (67) & 1 (Ref.) & & & & & \\
\hline Squamous cell carcinoma, primary (9) & 0.627 & $0.145-2.718$ & 0.533 & & & \\
\hline Adenoid cystic carcinoma, solid type (8) & 1.557 & $0.457-5.308$ & 0.479 & & & \\
\hline Mucoepidermoid carcinoma, high-grade (7) & 0.541 & $0.072-4.069$ & 0.550 & & & \\
\hline Adenocarcinoma, high-grade (6) & 0.439 & $0.058-3.302$ & 0.424 & & & \\
\hline Others (6) & 1.978 & $0.455-8.604$ & 0.363 & & & \\
\hline \multicolumn{7}{|l|}{ Treatment modalities } \\
\hline Surgery (13) & 1 (Ref) & & & 1 (Ref) & & \\
\hline Surgery + radiation (62) & 1.266 & $0.377-4.248$ & 0.702 & 0.742 & $0.207-2.655$ & 0.646 \\
\hline Surgery + radiation + chemotherapy (28) & 0.433 & $0.087-2.155$ & 0.307 & 0.121 & $0.022-0.677$ & 0.016 \\
\hline Surgery for primary tumor (R1/R0) (6/97) & 0.045 & $0.000-39.169$ & 0.369 & & & \\
\hline Neck dissection/no neck dissection (72/31) & 1.871 & $0.780-4.488$ & 0.161 & & & \\
\hline \multicolumn{7}{|l|}{ Pathological risk factors } \\
\hline Perineural invasion (Y/N) (13/90) & 0.042 & $0.000-12.297$ & 0.274 & & & \\
\hline Lymphovascular invasion (Y/N) (16/87) & 0.043 & $0.000-20.431$ & 0.317 & & & \\
\hline Extra-parenchymal extension (Y/N) (45/58) & 2.156 & $0.979-4.750$ & 0.057 & & & \\
\hline Extra-capsular spread (Y/N) (26/77) & 2.547 & $1.065-6.092$ & 0.036 & 1.363 & $0.509-3.649$ & 0.538 \\
\hline
\end{tabular}

Abbreviation:

$H R$ hazard ratio, $\mathrm{Cl}$ confidence interval

R1 resection: Cancer cells present at the resection margin, R0 resection: Cancer cells absent at the resection margin

Others (Pathological diagnosis): Atypical high-grade carcinoma, high-grade carcino-sarcoma, poorly differentiated carcinoma

Y: presence, $\mathrm{N}$ : absence

high-grade salivary gland cancers also had a similar clinical course (Fig. 3). Solid subtype of adenoid cystic carcinoma is a distinct form, different from the cribriform or tubular subtypes, which also has frequent lymph node and distant metastases, with a relatively rapid disease progression [26]. Therefore, our findings and the previous reported results suggest a clinical approach to salivary gland tumor suspicious of high-grade salivary gland cancer as a whole [6]. These results provide a clinical implication on the management strategy of salivary gland neoplasm that pre-operative workup might focus on the discrimination of tumor grade rather than the discrimination of specific pathological subtype (Fig. 4).

Frequently, current pre-operative diagnostic work-ups could not differentiate the specific pathological subtypes of high-grade salivary gland cancer with an enough diagnostic accuracy [7]. However, molecular or genetic testing to understand tumor biology and estimated prognosis are now developing [31, 32], which could be helpful even in the pre-operative settings. Previously, we reported that fine needle aspiration cytology could detect high-grade tumors with an acceptable diagnostic accuracy (90\%), although it has difficulty in discriminating benign versus malignant disease [7, 22]. Core needle biopsy may also be beneficial to differentiate high-grade pathology. Thus, fine needle aspiration cytology or core needle biopsy with appropriate radiological work-up can be sufficient for differential diagnoses of benign/low-grade malignancies and high-grade malignancies in pre-treatment evaluation and treatment decision for salivary gland tumor (Fig. 4). 

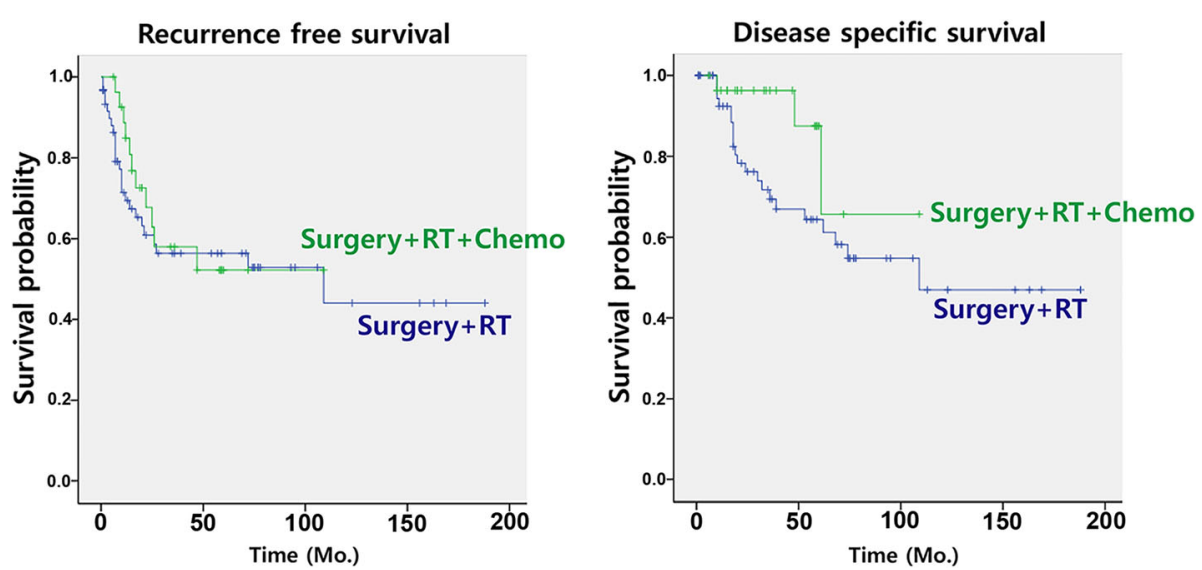

Fig. 2 Comparison of survivals between the two treatment strategies: surgery plus post-operative radiation versus surgery plus post-operative radiation and chemotherapy for high-grade salivary gland cancer

With respect to the salivary lesions suspicious for high-grade salivary gland cancer, pre-treatment workup for metastasis seems mandatory, because in our case series, approximately $50 \%$ of high-grade salivary gland cancers had lymph node metastasis at diagnosis, and $12 \%$ of high-grade salivary gland cancers had distant metastasis. A recent study also showed that $56 \%$ of patients had lymph node metastasis at diagnosis even in early $\mathrm{T}$ stage salivary duct carcinoma [33]. Initial surgery for resectable high-grade salivary gland cancers should include the complete removal of primary tumors and the potential nodal metastasis. In addition, adjuvant radiation with/without chemotherapy is recommended for high-grade salivary gland cancers [23]. In fact, most patients of early stage high-grade salivary gland cancers in our study had received adjuvant radiation because previous evidence already showed that the adjuvant radiation in salivary gland cancer with risk factors including high grade pathology increased the patient survivals [34,35].
However, the role of adjuvant chemoradiation is still controversial [34] and under Phase 3 clinical trials (ClinicalTrials.gov Identifier: NCT01220583). Collectively, we suggest a clinical management strategy for high-grade salivary gland cancer, which includes tumor grade-based diagnostic work-ups and management, surgery with adjuvant radiation and/or chemotherapy for high-grade or low-grade salivary gland cancer with risk factors (Fig. 4).

To gain better treatment outcomes in high-grade salivary gland cancers, we cautiously suggest a screening program (self-palpation or imaging) for patients susceptible to salivary gland tumor (e.g. family history, susceptible age), such as many other solid cancers. Indeed, as demonstrated previously (Fig. 1), early detection of high-grade salivary gland cancer before the occurrence of clinical metastasis appears to be the best option for improving outcomes of these patients, because patients diagnosed as having high-grade salivary gland cancer without metastasis have a high chance of cure from these devastating
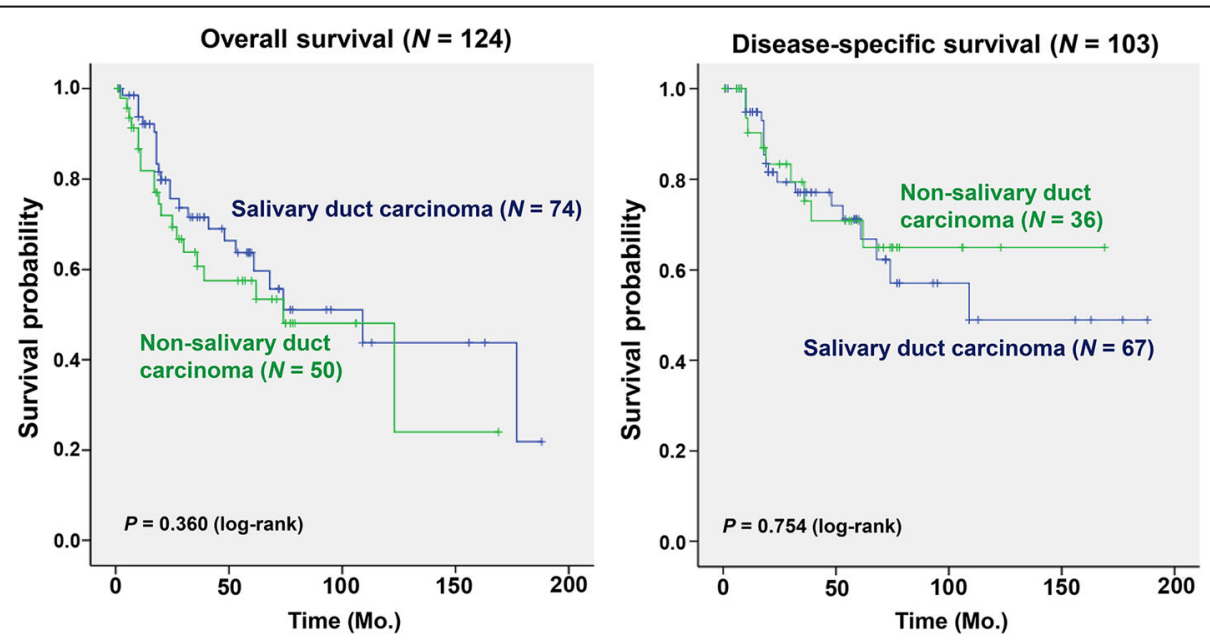

Fig. 3 Comparison of survivals in patients diagnosed with salivary duct carcinomas and non-salivary duct carcinoma pathologies 


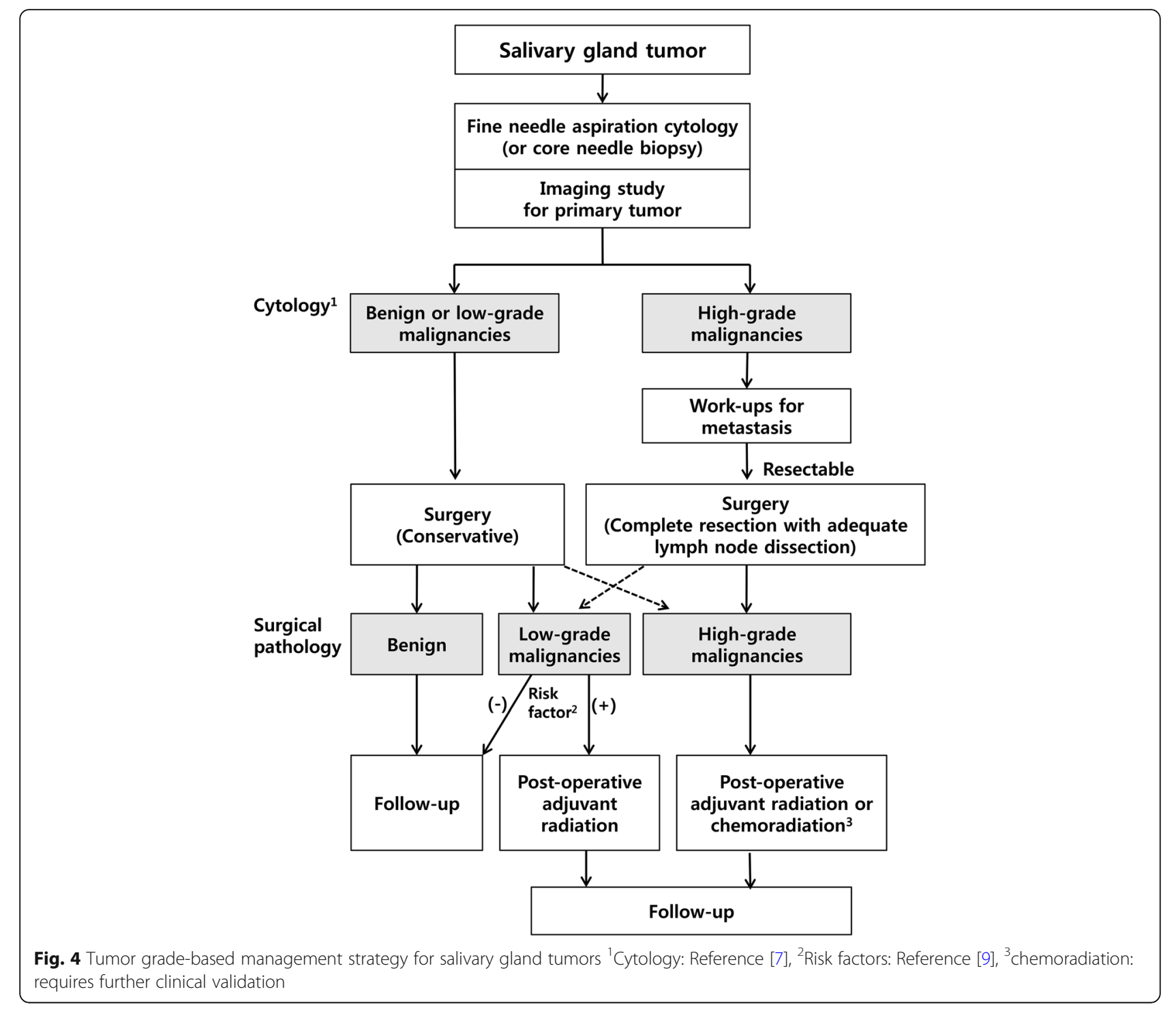

diseases. Majorities of salivary gland cancer arise from the parotid gland and submandibular gland which are easily palpable, thus education program of self-palpation might be effective for detecting the neoplasm in early-stage.

This study had several limitations, which the readers should keep in mind while interpreting our results. As mentioned earlier, the study collected clinical data retrospectively; therefore we could not compare the survival benefit of each treatment modality without selection bias. Therefore, superiority and benefit of postoperative adjuvant multimodal treatment should be re-evaluated in future prospective studies. In addition, we included a relatively large number of high-grade salivary gland cancer patients from a total of 540 patients with salivary gland cancers into our analyses; however the number of subjects was still not enough because some subtypes of high-grade salivary gland cancers are very rare. Thus, it was possible that our combined results did not reflect the unique features of rare subtypes of high-grade salivary gland cancers. Nevertheless, we think that our clinical approach based on high-grade pathology seems to be clinically practical, because of disease rarity and pathological diversity. Recently, a similar simplified, but combined approach to adenoid cystic carcinoma has been proposed, suggesting the differentiation of solid versus non-solid components [26].

\section{Conclusions}

Our data demonstrated that the presence of metastasis (nodal or distant) was the most significant prognostic factor for worse survival among patients with high-grade salivary gland cancers. Considering that the prognosis of early stage high-grade salivary gland cancer was relatively favorable, a public screening program, for example a self-palpation or education for general population might be helpful to detect high-grade salivary gland cancer in early-stage. 


\section{Abbreviations}

DFS: disease-specific survival; OS: overall survival.; RFS: recurrence-free survival; TNM staging: Tumor-node-metastasis staging

\section{Author's contributions}

JYJ: Collection and analysis of data, manuscript writing; NC: Collection and analysis of data; YHK: Pathological analyses; MKC \& YIS \& CHB: Collect and contribution of data, supervision; KHB and HSJ: Conceptual design, supervision, critical revision of intellectual contents. All authors read and approved the final manuscript.

\section{Funding}

This work was supported by the National Research Foundation of Korea grants funded by the Korean Government MEST (Nos. 2015R1D1A1A09056771 and 2016R1D1A1B03932867) and Samsung Biomedical Research Institute (SBRI) 2016 basic-clinical collaborative research grant. (SMX1161461). The above funders had no further role in the study design, in collection, analysis and interpretation of data, in writing of the manuscript, or in the decision to submit this manuscript for publication.

\section{Availability of data and materials}

All data generated or analyzed during this study are included in this published article and its supplementary information file.

\section{Consent to publish}

Not applicable

\section{Ethics approval and consent to participate}

The study protocol was approved by the Institutional Review Board of Samsung Medical Center. The written informed consent was not required for this retrospective study. The data used in this study was de-identified.

\section{Competing interests}

The authors declare that they have no competing interests.

\section{Publisher's Note}

Springer Nature remains neutral with regard to jurisdictional claims in published maps and institutional affiliations.

\section{Author details}

'Department of Otolaryngology, Ajou University School of Medicine, Suwon, Republic of Korea. 'Department of Otorhinolaryngology - Head and Neck Surgery, Samsung Medical Center, Sungkyunkwan University School of Medicine, 81 Irwon-ro, Gangnam-gu, Seoul 06351, Republic of Korea. ${ }^{3}$ Department of Pathology, Samsung Medical Center, Sungkyunkwan University School of Medicine, Seoul, Republic of Korea. ${ }^{4}$ Department of Molecular and Cellular Biology, Samsung Biomedical Research Institute, Sungkyunkwan University School of Medicine, Suwon, Republic of Korea.

\section{Received: 28 February 2018 Accepted: 7 June 2018}

Published online: 20 June 2018

\section{References}

1. Spiro RH. Salivary neoplasms: overview of a 35-year experience with 2,807 patients. Head \& neck surgery. 1986;8(3):177-84.

2. de Ridder M, Balm AJ, Smeele LE, Wouters MW, van Dijk BA. An epidemiological evaluation of salivary gland cancer in the Netherlands (1989-2010). Cancer Epidemiol. 2015:39(1):14-20.

3. El-Naggar AK. Tumours of salivary glands. In: El-Naggar AK, JKC C, Grandis JR, Takata T, Slootweg PJ, editors. WHO Classification of Head and Neck Tumours. Lyon, France: WHO Press; 2017. p. 159-202.

4. Seethala RR, Stenman G. Update from the 4th edition of the World Health Organization classification of head and neck Tumours: tumors of the salivary gland. Head and neck pathology. 2017;11(1):55-67.

5. Adelstein DJ, Koyfman SA, El-Naggar AK, Hanna EY. Biology and management of salivary gland cancers. Semin Radiat Oncol. 2012;22(3):245-53.

6. Haderlein M, Scherl C, Semrau S, Lettmaier S, Uter W, Neukam FW, Iro H, Agaimy A, Fietkau R. High-grade histology as predictor of early distant metastases and decreased disease-free survival in salivary gland cancer irrespective of tumor subtype. Head Neck. 2016;38(Suppl 1):E2041-8.
7. Kim BY, Hyeon J, Ryu G, Choi N, Baek CH, Ko YH, Jeong HS. Diagnostic accuracy of fine needle aspiration cytology for high-grade salivary gland tumors. Ann Surg Oncol. 2013;20(7):2380-7.

8. Jeong HS, Chung MK, Son YI, Choi JY, Kim HJ, Ko YH, Baek CH. Role of 18FFDG PET/CT in management of high-grade salivary gland malignancies. J Nucl Med. 2007:48(8):1237-44.

9. Cho JK, Lim BW, Kim EH, Ko YH, Oh D, Noh JM, Ahn YC, Baek KH, Jeong HS. Low-grade salivary gland cancers: treatment outcomes, extent of surgery and indications for postoperative adjuvant radiation therapy. Ann Surg Oncol. 2016;23(13):4368-75.

10. Richter SM, Friedmann P, Mourad WF, Hu KS, Persky MS, Harrison LB. Postoperative radiation therapy for small, low-/intermediate-grade parotid tumors with close and/or positive surgical margins. Head Neck. 2012;34(7):953-5.

11. Johnston ML, Huang SH, Waldron JN, Atenafu EG, Chan K, Cummings BJ, Gilbert RW, Goldstein D, Gullane PJ, Irish JC, et al. Salivary duct carcinoma: treatment, outcomes, and patterns of failure. Head Neck. 2016;38(Suppl 1):E820-6.

12. Jayaprakash V, Merzianu M, Warren GW, Arshad H, Hicks WL Jr, Rigual NR, Sullivan MA, Seshadri M, Marshall JR, Cohan DM, et al. Survival rates and prognostic factors for infiltrating salivary duct carcinoma: analysis of 228 cases from the surveillance, epidemiology, and end results database. Head Neck. 2014;36(5):694-701.

13. Otsuka K, Imanishi Y, Tada Y, Kawakita D, Kano S, Tsukahara K, Shimizu A, Ozawa H, Okami K, Sakai A, et al. Clinical outcomes and prognostic factors for salivary duct carcinoma: a multi-institutional analysis of 141 patients. Ann Surg Oncol. 2016;23(6):2038-45.

14. Gilbert MR, Sharma A, Schmitt NC, Johnson JT, Ferris RL, Duvvuri U, Kim S. A 20-year review of 75 cases of salivary duct carcinoma. JAMA otolaryngology- head \& neck surgery. 2016;142(5):489-95.

15. Nam SJ, Roh JL, Cho KJ, Choi SH, Nam SY, Kim SY. Risk factors and survival associated with distant metastasis in patients with carcinoma of the salivary gland. Ann Surg Oncol. 2016;23(13):4376-83.

16. Ali S, Bryant R, Palmer FL, DiLorenzo M, Shah JP, Patel SG, Ganly I. Distant metastases in patients with carcinoma of the major salivary glands. Ann Surg Oncol. 2015;22(12):4014-9.

17. Hong HR, Roh JL, Cho KJ, Choi SH, Nam SY, Kim SY. Prognostic value of lymph node density in high-grade salivary gland cancers. J Surg Oncol. 2015;111(6):784-9.

18. Nance MA, Seethala RR, Wang Y, Chiosea SI, Myers EN, Johnson JT, Lai SY. Treatment and survival outcomes based on histologic grading in patients with head and neck mucoepidermoid carcinoma. Cancer. 2008;113(8):2082-9.

19. Kim JW, Kwon GY, Roh JL, Choi SH, Nam SY, Kim SY, Cho KJ. Carcinoma ex pleomorphic adenoma of the salivary glands: distinct clinicopathologic features and immunoprofiles between subgroups according to cellular differentiation. J Korean Med Sci. 2011;26(10):1277-85.

20. Jegadeesh N, Liu Y, Prabhu RS, Magliocca KR, Marcus DM, Higgins KA, Vainshtein JM, Trad Wadsworth J, Beitler JJ. Outcomes and prognostic factors in modern era management of major salivary gland cancer. Oral Oncol. 2015;51(8):770-7.

21. Feinstein AJ, Alonso J, Yang SE, St John M. Diagnostic accuracy of fineneedle aspiration for parotid and submandibular gland lesions. Otolaryngology-head and neck surgery : official journal of American Academy of Otolaryngology-Head and Neck Surgery. 2016;155(3):431-6.

22. Rossi ED, Wong LQ, Bizzarro T, Petrone G, Mule A, Fadda G, Baloch ZM. The impact of FNAC in the management of salivary gland lesions: institutional experiences leading to a risk-based classification scheme. Cancer cytopathology. 2016;124(6):388-96.

23. Pfister DG, Ang KK, Brizel DM, Burtness BA, Cmelak AJ, Colevas AD, Dunphy F, Eisele DW, Gilbert J, Gillison ML, et al. Head and neck cancers. J Nat Compr Cancer Netw. 2011;9(6):596-650.

24. Edge SB, Compton CC. The American joint committee on Cancer: the 7th edition of the AJCC cancer staging manual and the future of TNM. Ann Surg Oncol. 2010;17(6):1471-4.

25. Szanto PA, Luna MA, Tortoledo ME, White RA. Histologic grading of adenoid cystic carcinoma of the salivary glands. Cancer. 1984;54(6):1062-9.

26. van Weert $S$, van der Waal I, Witte BI, Leemans CR, Bloemena $\mathrm{E}$. Histopathological grading of adenoid cystic carcinoma of the head and neck: analysis of currently used grading systems and proposal for a simplified grading scheme. Oral Oncol. 2015;51(1):71-6.

27. Batsakis JG, Luna MA. Histopathologic grading of salivary gland neoplasms: I. Mucoepidermoid carcinomas. Ann Otol Rhinol Laryngol. 1990;99(10 Pt 1):835-8. 
28. Seethala RR. An update on grading of salivary gland carcinomas. Head and neck pathology. 2009;3(1):69-77.

29. Osborn V, Givi B, Lee A, Sheth N, Roden D, Schwartz D, Schreiber D. Characterization, treatment and outcomes of salivary ductal carcinoma using the National Cancer Database. Oral Oncol. 2017;71:41-6.

30. Ali S, Palmer FL, Yu C, DiLorenzo M, Shah JP, Kattan MW, Patel SG, Ganly I. Postoperative nomograms predictive of survival after surgical management of malignant tumors of the major salivary glands. Ann Surg Oncol. 2014; 21(2):637-42.

31. Griffith CC, Schmitt AC, Little JL, Magliocca KR. New developments in salivary gland pathology: clinically useful ancillary testing and new potentially targetable molecular alterations. Arch Pathol Lab Med. 2017; 141(3):381-95.

32. Skalova A, Stenman G, Simpson RHW, Hellquist H, Slouka D, Svoboda T, Bishop JA, Hunt JL, Nibu Kl, Rinaldo A, et al. The role of molecular testing in the differential diagnosis of salivary gland carcinomas. Am J Surg Pathol. 2018;42(2):e11-e27.

33. Schmitt NC, Sharma A, Gilbert MR, Kim S. Early T stage salivary duct carcinoma: outcomes and implications for patient counseling. Otolaryngology-head and neck surgery : official journal of American Academy of Otolaryngology-Head and Neck Surgery. 2015;153(5):795-8.

34. Mifsud MJ, Tanvetyanon T, McCaffrey JC, Otto KJ, Padhya TA, Kish J, Trotti AM, Harrison LB, Caudell JJ. Adjuvant radiotherapy versus concurrent chemoradiotherapy for the management of high-risk salivary gland carcinomas. Head Neck. 2016;38(11):1628-33.

35. Hosni A, Huang SH, Goldstein D, Xu W, Chan B, Hansen A, Weinreb I, Bratman SV, Cho J, Giuliani M, et al. Outcomes and prognostic factors for major salivary gland carcinoma following postoperative radiotherapy. Oral Oncol. 2016;54:75-80.

Ready to submit your research? Choose BMC and benefit from:

- fast, convenient online submission

- thorough peer review by experienced researchers in your field

- rapid publication on acceptance

- support for research data, including large and complex data types

- gold Open Access which fosters wider collaboration and increased citations

- maximum visibility for your research: over $100 \mathrm{M}$ website views per year

At BMC, research is always in progress.

Learn more biomedcentral.com/submissions 